\section{Duchenne muscular dystrophy: early diagnosis, and screening}

Sir,

Some important questions are raised by Gilboa and Swanson (1976) in their paper and by Dubowitz in his annotation and letter (1976a, b) in your April issue. The use of cord blood samples for serum creatine kinase (CPK) estimation for the early diagnosis of Duchenne muscular dystrophy has been discussed for more than 10 years, so it comes as a shock to realize that no one has reported actually doing it. We have had some experience now and the family reactions have been illuminating.

Family I. Eileen, aged 19, had seen a brother and a maternal uncle die with Duchenne muscular dystrophy, and a younger affected brother was 14 . When she was pregnant her obstetrician sent her for genetic advice. Her mother (a definite carrier) who had never discussed the position with the family, had a serum CPK of $77 \mathrm{IU}$ (method of Pearce, Pennington, and Walton (1964), normal range up to $75 \mathrm{IU}$ ). The daughter's serum CPK at 14 weeks of pregnancy was nor$\mathrm{mal}$ at $25 \mathrm{IU}$. We had seen many definite carriers with normal CPK levels, so she was advised that there was still some risk and agreed to the baby being tested at birth. A boy was born in September 1967. The serum CPK level in a postal sample of cord blood was $1600 \mathrm{IU}$ and was confirmed with a fresh venous sample at the age of $2 \frac{1}{2}$ weeks (1433 IU). A muscle biopsy (also at $2 \frac{1}{2}$ weeks) showed abundant hyaline fibres but no necrotic or regenerating fibres, and was interpreted as confirming early muscular dystrophy. It was particularly difficult to tell the young parents, who understood the prognosis all too well, that their apparently normal baby would be affected. To palliate their feelings (and my own), oral Laevadosin was given daily for the first 3 years of life. The boy first showed an abnormality of gait at 1 year 11 months, and at 3 years had obvious early signs of muscular dystrophy. His serum CPK at 2 years 3 months was $6033 \mathrm{IU}$, at 3 years 2 months $2160 \mathrm{IU}$, and at 8 years 2 months $3964 \mathrm{IU}$. A second muscle biopsy at 3 years showed the typical features of active Duchenne muscular dystrophy. Now at 8 years, the clinical features are characteristic and of average severity.

Despite her distress and clear advice to use contraception, she then had 2 girls (born in 1968 and 1974), refused amniocentesis for sexing the fetuses, refused sterilization, and had a further son in 1975 . She and her husband delined offers to test the cord blood in the second and third pregnancies because they did not want to know, if they had a boy, whether he was going to be affected. They were not asked in the fourth pregnancy, but we took cord blood without their knowledge, found the CPK high again (1638 IU after 19 hours in the post) and decided with the family doctor's consent not to mention the result unless we were asked. This second boy is now aged 8 months, and has been brought to the clinic with his brother on several occasions, but his parents have not raised the question of his possible involvement, even when a glaring opportunity arose during a discussion of contraception and of the risks of further pregnancies.

Family II. Brian was referred in 1972 at age 5 with early Duchenne dystrophy confirmed by biopsy. There was no previous family history but his mother's serum CPK was 214 IU. She was then 37 weeks pregnant. Cord blood taken when her second son, Kevin, was born had a serum CPK level of $12750 \mathrm{IU}$. The parents were told that Brian had muscular dystrophy and that Kevin was probably also affected, but that our experience of cord blood CPK levels was slight and that a further CPK test would be needed to confirm the result if they wanted this to be done. They both preferred to wait. By 1975 Kevin showed early gait changes and the parents then asked to have the serum CPK checked. It was 13598 IU. There is a normal sister born in 1968. The father had a vasectomy shortly after Kevin's birth.

Family III. Rosalind's brother was an isolated case of Duchenne muscular dystrophy. Her CPK was tested routinely at age 15 and was $13.4 \mathrm{IU}$. The small risk that she was nevertheless a carrier was explained to her. At age 21 she became pregnant and had a son whose cord blood CPK level was 686 IU. We were incautious enough to give her the same advice as family II with the same result. At age 10 months, however, a muscle biopsy was normal and the serum CPK was 61 IU. 7 months later it had fallen to $30 \cdot 3 \mathrm{IU}$.

There are several conclusions to be drawn. (1) The CPK levels in cord blood in 2, and presumably 3 cases of Duchenne muscular dystrophy were well above the moderately raised levels found by Gilboa and Swanson, in 2 cases even after being sent by post. However, the normal boy in family III had nearly as high a level. The need for the result to be confirmed later is clear. (2) After living through the experience of having one child diagnosed at birth, the parents in family I not only clearly said that they did not want to do so again, but 
later, when nothing was said by the doctor, they repeatedly ignored opportunities to find out about their second son. The parents in family II, even in the period of stress soon after their first son's diagnosis, made the same decision. The actions of these parents actually exposed to the situation seem to me to speak louder than the words of the parents who replied to Professor Beckmann's questionnaire (Dubowitz, 1976a) by saying that they would want to know at birth whether their son was affected. However, the mother in family III suffered uncertainty and fear for a year because of our inexperienced interpretation of an apparently abnormal result. Deliberately leaving the matter unsettled can clearly work both ways. (3) The intelligent, experienced, and informed parents in family I illustrate the difference between genetic counselling to which, after a late start, they were exposed in full measure and compulsory eugenics from which it is tempting to think they might have profited. If they could ignore advice given on the basis of early diagnosis, one must not assume that parents whose child is detected by total population screening, and who will generally not have heard of muscular dystrophy, will react differently. There is no precedent for total population screening of infants with the sole purpose of giving genetic counselling. If it is introduced, its effectiveness will depend on more than just the reliability of the tests. The need for prevention, however, is illustrated by another family.

Family IV. Billy was referred at age 4. His abnormal gait was investigated and found to be due to Duchenne muscular dystrophy. There were no previous cases in the family but he already had 2 younger brothers aged 3 and 2 years, both of whom had very high CPK levels. The burden this family will have to bear over the next 15-20 years is appalling.

\section{DAVID GARDNER-MEDWIN Regional Neurological Centre, Newcastle General Hospital, Westgate Road, \\ Newcastle upon Tyne NE4 $6 B E$.}

\section{REFERENCES}

Dubowitz, V. (1976a). Screening for Duchenne muscular dystrophy. Archives of Disease in Childhood, 51, 249.

Dubowitz, V. (1976b). Genetic miscounselling in muscular dystrophy. Archives of Disease in Childhood, 51, 235.

Gilboa, N., and Swanson, J. R. (1976). Serum creatine phosphokinase in normal newborns. Archives of Disease in Childhood, 51, 283.

Pearce, J. M. S., Pennington, R. J., and Walton, J. N. (1964). Serum enzyme studies in muscle disease, Part 1 . fournal of Neurology, Neurosurgery and Psychiatry, 27, 1.

\section{Professor Dubowitz comments :}

I entirely agree with Dr. Gardner-Medwin that cord blood CPK is a useful screen in families at risk, and, like him, I have used it on a number of occasions. However, in view of the higher normal levels in cord blood, with an upper range of about 10 times the adult normal, one should reserve judgement on levels not grossly raised and within the usual infant Duchenne range (say over $1000 \mathrm{IU} / \mathrm{l}$ ), and should always confirm an abnormal result on a peripheral blood sample. This is well illustrated by Dr. Gardner-Medwin's family III.

If a screening programme for the general population were to be introduced in the future, should therapeutic possibilities become available, the only practical approach would be to do it in parallel with the phenylketonuric screen on the same blood sample. For the present I do not think one could justify such a general screening programme for Duchenne dystrophy purely for the purpose of genetic counselling.

VICTOR DUBOWITZ

Department of Paediatrics and Neonatal Medicine, Hammersmith Hospital, Du Cane Road, London W12 OHS.

Sir,

I have read with interest Professor Dubowitz's recent contributions in the Archives (1976, 51, 249 and 325). The problem of genetic screening for Duchenne muscular dystrophy (DMD) on a nationwide basis using creatine kinase (CPK) may be effective for case ascertainment, but is certainly tardy preventive medicine. Unless genetic counselling procedures for DMD are re-evaluated and revised, the impact of such a programme would be minimal. The usual counselling techniques are based on the indirect Haldane estimate of spontaneous new mutation rate and assume that approximately one-third of all cases are due to new mutations (Murphy and Mutalik, 1969; Haldane, 1935).

Recent data from studies of the X-linked lethal LeschNyhan disease, as well as from DMD, have questioned the validity of this approach. The frequency of mothers of affected sons showing heterozygosity for hypoxanthine-guanine phosphoribosyl-transferase (HPRT) deficiency is substantially greater than would be expected from theoretical considerations (Francke et al., 1976). Mothers of affected DMD patients seem to show a similar deficiency of new mutants though the data are more inferential since the inborn error has not been defined (Roses, 1976; Roses et al., 1976a, b).

Dubowitz is correct in his statement that a nationwide screening programme 'may seem meddlesome in a condition where no effective treatment is available. . $\therefore$. Recent experience with over 50 diseases that can be diagnosed in utero should underscore that the most effective current methods are those of prevention. Carrier detection is the crux of this approach (Milunsky et al., 1970).

While investigators are attempting to define the inborn error in DMD and develop prenatal and carrier identification methods, complete pedigree analyses of families of affected males should be undertaken using presently available techniques. Of course it should be emphasized that until the biochemical defect is defined all methods are inferential. Notwithstanding such criticism, mothers of affected sons and other female relatives with obviously raised CPK levels are currently being counselled as carriers in most clinics. There are a 